\title{
INTERACIONISMO SIMBÓLICO, FORMAÇÃO DO SELF E EDUCAÇÃO: UMA APROXIMAÇÃO AO PENSAMENTO DE G. H. MEAD
}

\section{Symbolic interactionism, the formation of the self and education: some approaches to G. H. Mead's thinking
Interaccionismo simbólico, formación del self y educación: una aproximación al pensamiento de G. H. Mead

\section{Cledes Antonio Casagrande*}

Resumo: Este artigo versa sobre a educação e o processo de formação do self na perspectiva do "interacionismo simbólico". Tem como objetivo principal esboçar uma aproximação ao pensamento de G. H. Mead, autor pouco conhecido na comunidade acadêmica brasileira, e estabelecer uma discussão teórica, com base em revisão de literatura, para o campo da teoria da educação. Para tanto, parte do seguinte problema: como podemos entender o processo de individuação do eu na perspectiva teórica de G. H. Mead e qual é a concepção de educação decorrente do "interacionismo simbólico"? Nossa opção pela teoria de G. H. Mead alinha-se à concepção de que nós, seres humanos, somos inscritos numa matriz intersubjetiva, interativa e simbólica por meio da qual, mediante processos de socialização e de aprendizagem, desenvolvemos uma identidade pessoal e estruturamos nossa personalidade.

Palavras-chave: Interacionismo simbólico. Educação. Identidade. Self. G. H. Mead.

Abstract: This article is about education and the process of self-formation from "symbolic interactionism" perspective. It aims to sketch an approach

Doutor em Educação pela Pontifícia Universidade Católica do Rio Grande do Sul. Professor colaborador do Programa de Pós-Graduação em Educação do Centro Universitário La Salle de Canoas, RS.E-mail: cledes.casagrande@lasalle.org.br 
to Mead"s thinking, yet little known in the Brazilian academic community, as well as establish a discussion within the field of theory of education. Therefore, we start from the following problem: according to Mead, how can we understand the process of individuation of the self, and what is the conception of education deriving from his "symbolic interactionism"? Mead"s theory fits in the understanding that we, human beings, are inscribed in an intersubjective, interactive and symbolic matrix in which, through processes of socialization and learning, we develop a personal identity and structure our personality.

Keywords: Symbolic interactionism. Education. Identity. Self. G. H. Mead.

Resumen: Este artículo aborda la educación y el proceso de formación del self desde la perspectiva del "interaccionismo simbólico". Su principal objetivo consiste en esbozar una aproximación al pensamiento de G. H. Mead, autor poco conocido en la comunidad académica brasileña, y establecer una discusión teórica basada en la revisión de la literatura para el campo de la teoría de la educación. Por lo tanto, se basa en la siguiente cuestión: ¿Cómo es posible entender el proceso de individuación del yo en la perspectiva teórica de G. H. Mead y cuál es el concepto de educación derivado del "interaccionismo simbólico"? Nuestra opción por la teoría de G. H. Mead se alinea con la comprensión de que los seres humanos están inscritos en una matriz intersubjetiva, interactiva y simbólica a través de la cual, y por medio de los procesos de socialización y aprendizaje, desarrollan una identidad personal y estructuran la personalidad.

Palabras clave: Interaccionismo simbólico. Educación. Identidad. Self. G. H. Mead.

\section{Introdução}

O tema da formação do eu tem sido recorrente na literatura das Ciências Humanas, especialmente na sua interface com a Educação. Essa recorrência, longe de significar consenso ou unidade, denota que provavelmente estamos 
num campo de teorias múltiplas, antagônicas e, por vezes, contraditórias. Percebemos que essa multiplicidade de perspectivas enseja também certa crise conceitual, própria do contexto do pensamento pós-metafísico ${ }^{1}$, característica marcante de nossa época. Além disso, observamos o surgimento de um quadro de desestabilização dos conceitos e modelos tradicionais de subjetividade e de identidade ${ }^{2}$ e, consequentemente, de alguns dos referenciais que dão suporte aos processos formativos escolares.

Entendemos que a abordagem de George Herbert Mead (1863-1931) acerca da constituição da identidade do eu, especialmente o conceito de self ou "si mesmo" 3 e a noção de interação simbólica, representam um renovado potencial de compreensão do papel da educação na formação das pessoas e na constituição da personalidade. Denotam, também, possibilidades de compreensão dos processos formativos escolares não apenas pela perspectiva da formação intelectual, abrindo espaço à interação, à socialização, ao brincar e à experiência estética.

1 Por pensar pós-metafísico entendemos o empreendimento teórico despido das esperanças e das tentativas de fundamentação de caráter ontológico ou dedutivo; um modo pensar que renuncia o recurso ao transcendental e às Referências extramundanas de legitimação e de justificação do ser, do agir e do conhecer. Habermas (2002, p. 43) concebe o pensar pós-metafísico a partir de quatro características: suspensão do pensamento totalizador; destranscendentalização dos conceitos tradicionais e resgate das dimensões históricas da finitude e da contingência; desenvolvimento da filosofia da linguagem como crítica à filosofia da consciência; inversão do primado da teoria sobre a prática.

2 Segundo Nunner-Winkler (2011, p. 59), atualmente, novos modos de compreensão da identidade pessoal são forjados em oposição às concepções mais estáveis, unitárias e tradicionais de identidade; eles são expressos em termos como "mentalidade artesanal, patchwork identity, o sujeito plural, identidade como collage".

3 No presente texto optamos por manter o termo self em sua grafia original no inglês. A melhor tradução, em nosso entender, seria "si mesmo". Os textos que tivemos acesso em língua espanhola utilizam o termo "persona", como no caso da tradução de "Mind, self and society" (MEAD, 1992), traduzido por "Espíritu, persona y sociedad" (MEAD, 1973). Entretanto, percebemos que os termos correspondentes em português - pessoa, personalidade, eu, caráter e ego - não expressam integralmente o significado original do termo self. Odair Sass (2004), um dos poucos autores brasileiros que estudaram com mais profundidade a obra de Mead, também optou por manter a grafia original do termo em inglês, visto que expressa de modo mais adequado o significado e o contexto no qual ele é aplicado. A tradutora do livro de Filipe Carreira da Silva (2009), Vera Pereira, também manteve a grafia do termo self em inglês. 
Ressaltamos que o tema abordado neste artigo é um recorte de uma pesquisa mais ampla que desenvolvemos em anos anteriores (CASAGRANDE, 2012; 2014). ${ }^{4}$ Seguindo a mesma temática, embora com uma formulação distinta, este artigo buscará desenvolver o seguinte problema: como podemos entender o processo de individuação do eu na perspectiva teórica de G. H. Mead e qual a concepção de educação decorrente do "interacionismo simbólico"? ${ }^{5}$

Mead, autor pouco conhecido no meio acadêmico brasileiro e um dos fundadores do pragmatismo americano, ${ }^{6}$ destacou-se entre os pensadores do início do século XX por sua originalidade na abordagem da constituição social do self. O modelo dessa abordagem era o da interação simbólica, segundo o qual ao menos dois organismos reagem um ao outro por meio de ações e expressões comunicativas recíprocas. Esse modelo é comumente denominado "interacionismo simbólico", designação cunhada por Herbert Blumer ao chamar de "interacionistas simbólicos" os autores pragmatistas que compartilhavam uma posição teórica similar em relação ao fenômeno da evolução da vida humana, da conduta dos indivíduos e da evolução da sociedade, compreendendo-os enquanto processos de interação simbólica ${ }^{8}$.

4 Referimo-nos à Tese de Doutorado em Educação, orientada pela Professora Doutora. Nadja Hermann, intitulada "A formação do eu em Mead e em Habermas: desafios e implicações à educação" (CASAGRANDE, 2012), e ao livro "G. H. Mead \& a Educação" (CASAGRANDE, 2014).

5 Agradecemos as contribuições e as sugestões recebidas dos revisores do texto, bem como a revisão ortográfica e gramatical realizada pela estudante Gisele Schmidt Moitoso, bolsista voluntária de iniciação científica, as quais muito qualificaram este artigo.

6 O pragmatismo, em sua acepção original, possuía um tríplice pilar de estruturação: a doutrina da evolução biológica, a confiança na ciência com seu método experimental e a tradição democrática. Para Biesta e Burbules (2003, p. 4), "o pragmatismo tem sido caracterizado como uma expressão filosófica da típica mentalidade americana", além de ser considerado o primeiro movimento filosófico original de pensadores americanos.

7 Ressaltamos que Herbert Blumer (1969, p. 1) assume ter cunhado o termo "interacionismo simbólico", em um artigo do ano de 1937, reconhecendo-o, posteriormente, como um "neologismo bárbaro", que passou a ser amplamente utilizado. Odair Sass (2004, p. 169), na nota 18, também dá ênfase a essa mesma ressalva. Ademais, conforme assevera Hans Joas (1997, p. 228), na nota explicativa 5, o termo "interacionismo simbólico" não foi, de fato, criado ou empregado por G. H. Mead em seus escritos.

8 Uma primeira aproximação ao tema do "interacionismo simbólico" pode ser encontrada, em língua portuguesa, no texto denominado "Interacionismo simbólico" de Hans Joas (1999, p. 127-174). 
Ao analisarmos a obra de Mead, a noção de self ou "si mesmo", numa perspectiva pós-metafísica, destaca-se como um dos principais temas abordados. Para esse autor, a mente, a consciência e o self são constituídos na convivência social e estruturam-se simbolicamente, numa matriz intersubjetiva, o que aproxima o processo de individuação ao de socialização. Ele parte da oposição entre as teorias individualistas e sociais da pessoa humana, posicionando-se em favor de uma concepção social da emergência do self, sem relegar a um segundo plano a dimensão subjetiva. Supera, desse modo, a concepção de indivíduo e de sociedade enquanto entes fechados e mutuamente excludentes.

Com relação aos processos formativos e educacionais, constituem temas caros ao referido autor: o papel da comunicação na estruturação simbólica do eu, os processos de aprendizagem numa perspectiva social, enquanto catalisadores da formação da identidade individual e da possibilidade de reprodução de uma forma democrática de sociedade, e o progressivo desenvolvimento das estruturas internas, que ocorrem especialmente na etapa da infância e da adolescência (CASAGRANDE, 2014).

Tendo presente esse panorama inicial, e buscando responder ao problema proposto, estruturamos nosso texto a partir do seguinte esquema: uma aproximação ao conceito de "interacionismo simbólico" e suas implicações nos escritos de G. H. Mead [1], a gênese e a estrutura dialética do self, com ênfase na dinâmica do brincar e do jogar [2] e o papel da educação nos processos formativos [3].

\section{Sobre o "interacionismo simbólico" e suas implicações em G. H. Mead}

Mead parte do pressuposto de que a vida organiza-se e desenvolve-se sob um fundamento social e que o self possui estruturação simbólica. Isso implica considerar três premissas fundamentais: ${ }^{9}$ [i] o reconhecimento categórico do caráter intersubjetivo e social da vida humana e a anterioridade da sociedade em relação ao indivíduo, ${ }^{10}[\mathrm{ii}]$ a indissociabilidade entre o sujeito

9 Essas três premissas foram trabalhadas, de modo mais detalhado, em outro texto do autor (CASAGRANDE, 2014, p. 21-53).

10 Na presente leitura da obra de G. H. Mead, alinhamo-nos à interpretação de Odair Sass (2004, p. 98), que ao acentuar o caráter social da vida humana optou por ressaltar a precedência do todo social em relação ao indivíduo, invertendo a lógica de exposição 
e a sociedade e [iii] a centralidade da comunicação simbólica enquanto elemento responsável pela estruturação do self e pela evolução da comunidade humana. Essas três premissas, tomadas em seu conjunto, configuram o que podemos denominar elementos constitutivos do "interacionismo simbólico", como veremos na sequência.

[i] o reconhecimento categórico do caráter intersubjetivo e social da vida humana

A intersubjetividade possui papel relevante nos escritos de Mead, sendo apontada por Gert Biesta (1999, p. 203), como uma "intersubjetividade radical", o que configura uma posição de destaque à dimensão social da vida humana. Mead entende que todos os organismos vivos são sociais por natureza e dependentes da vida social, pois "não há organismo vivo, de qualquer espécie, cuja natureza ou constituição seja tal que possa existir ou manter-se em completo isolamento de todos os demais organismos vivos" (MEAD, 1992, p. 228) ${ }^{11}$ O mesmo ocorre com o ser humano, que necessita de outros seres humanos para nascer, crescer, subsistir e se desenvolver enquanto pessoa.

Mead denomina sociabilidade (sociality) o caráter social inerente à vida, um conceito que contém a tentativa de situar a natureza e a evolução da vida humana a partir de bases sociais. A sociabilidade está relacionada a todos os níveis da vida do ser humano, desde o físico, o orgânico até o desenvolvimento da mente e do self. Para fundamentar o caráter originalmente social da vida do ser humano, Mead recorre a uma analogia entre a sociedade humana e outras sociedades animais, como as de insetos. Afirma que todas as formas sociais de vida, inclusive as de animais inferiores, estão pautadas em relações sociais, as quais se constituem na base da emergência, da manutenção e da evolução dessas sociedades (MEAD, 1984; 1992).

presente em Mind, Self and Society (MEAD, 1992). David Miller (1973), Gert Biesta (1998) e Filipe Carreira da Silva (2009) também acentuam, em suas exposições, a precedência e a importância da dimensão social frente à dimensão individual no processo de formação do self.

11 Todos os textos em língua estrangeira utilizados neste artigo foram traduzidos, livremente, pelo autor deste artigo. 
A intersubjetividade, a linguagem e a capacidade de comunicação simbólica diferenciam os seres humanos dos outros animais. A diferença qualitativa da sociedade humana em relação às outras sociedades animais está pautada no desenvolvimento de um universo discursivo, no modo de comunicação simbólica e na participação cooperativa em atividades comuns, visto que "a sociedade humana depende, para sua forma de organização distintiva, do desenvolvimento da linguagem" (MEAD, 1992, p. 235).

[ii] a indissociabilidade entre o sujeito e a sociedade

O postulado da indissociabilidade entre indivíduo e sociedade é central na obra de Mead. Esse postulado nivela e correlaciona ontogênese e filogênese e pressupõe que, ambos, indivíduo e sociedade, constituam-se mutuamente. Nessa perspectiva, a sociedade é condição de emergência do self, e este se constitui na base ou no pressuposto da evolução da sociedade. A história da espécie humana (filogenia) e a história das pessoas individualmente (ontogenia) são processos indissociáveis, pois a filogênese e a ontogênese são dois aspectos distintos do mesmo processo evolutivo.

Seguindo essa mesma argumentação, Silva $(2009$, p. 16) afirma que "ontogênese e filogênese são duas facetas do mesmo processo evolutivo". Em outra passagem, Silva (2009, p. 162) esclarece que, em Mead, a "explicação genética da consciência baseou-se na ideia de que a história da espécie e a história do self são processos interligados". Desse modo, se, por um lado, a existência da sociedade e, especialmente da comunicação simbólica, consiste na precondição do desenvolvimento da pessoa humana, por outro, são as pessoas que possibilitam a existência de uma sociedade distintivamente humana.

A indissociabilidade sujeito-sociedade implica, por consequência, o reconhecimento do caráter intersubjetivo da vida humana. Destarte, podemos dizer que uma das grandes contribuições de Mead consiste na afirmação de que a subjetividade e a consciência são produtos da intersubjetividade e da interação simbólica, visto que "a interação social precede e produz consciência reflexiva" (BIESTA, 1998, p. 91). Ou seja, é na rede das relações simbólicas e intersubjetivas que o self e a sociedade encontram condições para estruturarem-se e desenvolverem-se. 
[iii] a centralidade da interação simbólica

Hans Joas (1997), ao analisar a teoria antropológica de Mead e sua relação com a linguagem e a comunicação, aponta a originalidade e o papel central que ocupa o conceito de "interação simbólica". Para Mead (1992, p. 244), no ser humano, a diferenciação funcional por meio da linguagem "proporciona um princípio inteiramente diferente de organização, que produz não somente um tipo inteiramente distinto de indivíduo, mas também uma sociedade diferente". Por intermédio do uso da linguagem e de símbolos significantes, o indivíduo internaliza as atitudes do seu grupo social. Adota, em relação a si mesmo, a mesma atitude que a comunidade adota em relação a ele. Isso implica um processo de estruturação complexo, pautado na comunicação e na participação, que abre inúmeras possibilidades de organização da consciência e da sociedade.

Conforme mencionamos anteriormente, o modelo de abordagem de Mead é o da interação simbólica, "um tipo de interação no qual se utilizam símbolos e gestos significativos" (BLUMER, 2003, p. 22). Num elucidativo texto de 1969, intitulado Symbolic interactionism: perspective and method, Herbert Blumer (1969, p. 6-20) sintetiza as raízes conceituais do "interacionismo simbólico" como fundamentadas nos seguintes temas: natureza da sociedade humana ou da vida do grupo humano; natureza da interação social; natureza dos objetos; o ser humano como um organismo de ação; natureza da ação humana e a interconexão das linhas de ação. Para Blumer, o termo "interação simbólica" refere-se primariamente às ações de interação linguística que envolvem palavras, símbolos verbais e significados. Nesse sentido, podemos dizer que a teoria do "interacionismo simbólico" repousa sobre três premissas básicas:

A primeira premissa é que os seres humanos agem em relação às coisas com base no significado que essas coisas possuem para eles. Essas coisas incluem tudo o que o ser humano pode notar em seu mundo [...]. A segunda premissa é que o significado de tais coisas deriva ou surge da interação social que cada um estabelece com seus semelhantes. A terceira premissa é que esses significados são manuseados e modificados pelas pessoas por meio de um processo interpretativo, no trato com as coisas que elas encontrarem (BLUMER, 1969, p. 2). 
Além do acento na noção de significado como um produto oriundo da interação dos distintos sujeitos sociais, o "interacionismo simbólico", na vertente consolidada por Herbert Blumer, possuía uma abordagem metodológica distinta em relação às ciências empíricas. Na perspectiva do "interacionismo simbólico", a compreensão da realidade do mundo pressupõe a análise das ações e das interações dos sujeitos como seres implicados na investigação, diferente das ciências empíricas, para as quais apenas os dados empíricos e quantitativos que seguiam um protocolo tinham importância. O pesquisador é, como sujeito social, intérprete e partícipe de seu mundo, responsável pela exploração e pela inspeção da própria realidade. Segundo Blumer (1969, p. 46), a exploração e a inspeção, como opções metodológicas do interacionismo, "representam a descrição e a análise, constituindo-se no procedimento necessário para o exame do mundo empírico social". Trata-se de um procedimento que salvaguarda e mantém o rigor teórico, mas que também implica o sujeito na análise da própria realidade social da qual ele é partícipe.

Como temos visto, Mead atribui à comunicação, enquanto interação simbólica, um papel central na emergência e na evolução do indivíduo e da sociedade. Entende que no gesto reside o princípio originário da comunicação humana. Por isso, ele diferencia os gestos simples dos gestos significativos, aqueles gestos carregados de significado. Para que um gesto seja significativo, expresse um símbolo inteligível para mais de um indivíduo, é necessário que ele seja internalizado. Por conseguinte, cada ser humano necessita desenvolver o mecanismo de internalização dos gestos e das atitudes dos outros.

O mecanismo de "adotar a atitude do outro", conceito largamente utilizado, consiste numa chave para a compreensão da psicologia social e do esquema de desenvolvimento do self nos escritos de Mead. De acordo com Cook (1993, p. 92), é possível encontrar várias aplicações desse mecanismo:

1) ele demarca a aquisição dos símbolos significantes; 2) torna possível o diálogo interior do pensamento humano; 3) é o mecanismo comportamental por meio do qual o indivíduo obtém a autoconsciência; 4) é o responsável pelo desenvolvimento da estrutura social da personalidade ou do self humano; 5) ele fornece o princípio distintivo da organização social humana; 6) habilita o indivíduo humano a participar no mundo de objetos compartilhados ou públicos. 
O processo de adoção da atitude do outro pressupõe o desenvolvimento de um comportamento cooperativo e um alinhamento em relação aos projetos, anseios, desejos e discursos do grupo social no qual o sujeito está inserido. Ao tornar-se parte do grupo, o indivíduo assume um modo de linguagem, um universo discursivo específico, passando a comunicar-se de modo semelhante aos outros membros do grupo. Para Mead, esse é o mecanismo que instaura o processo que dá origem ao pensamento e à identidade individual.

\section{A gênese e a estrutura interna do "self"}

Os escritos de Mead demonstram que a noção de self é construída sob a lógica dos processos de interação, numa matriz intersubjetiva e simbólica, pois "a individuação só é possível pela via da socialização" (HABERMAS, 2012, p. 672). A gênese do self, enquanto uma autocompreensão reflexiva, ocorre no seio social, por meio da inserção do indivíduo nos processos de comunicação e da consequente internalização das estruturas simbólicas presentes na linguagem.

Ao comentar a questão da gênese do self, Charles Morris (1992, p. XXIII) afirma que a mediação da linguagem é que torna possível a emergência do self, uma vez que "o self, a mente, a "consciência de" e o símbolo significante são, em certo sentido, precipitados juntos". Ou seja, é na conduta social que os processos de individuação e socialização dos seres humanos são desenvolvidos. Ademais, é por meio da conduta social que as estruturas do self e da consciência de si têm a possibilidade de se estruturarem.

As pessoas [selves] somente podem existir em relações definidas com outras pessoas. [...] O indivíduo possui um self somente em relação com os selves dos outros membros do seu grupo social; e a estrutura de seu self expressa ou reflete o padrão geral de comportamento do grupo social ao qual pertence, assim como o faz a estrutura do self de todos os demais indivíduos pertencentes a esse grupo social (MEAD, 1992, p. 164).

A citação anterior demonstra que o ser humano humaniza-se e individualiza-se mediante processos de socialização. Dessa maneira, para Mead (1992, p. 140), "o self, enquanto objeto para si mesmo, é essencialmente uma 
estrutura social e surge da experiência social", sendo impossível conceber essa noção de "si mesmo" desacoplada da vida em sociedade, da interação entre os diversos sujeitos e do processo de internalização das estruturas simbólicas presentes na linguagem.

Ele [o indivíduo] se converte em um self na medida em que pode adotar a atitude de outro e atuar em direção a si mesmo como atuam os outros. [...] O que constitui um selfé o processo social de influenciar sobre outros num ato social e, em seguida, adotar a atitude dos outros, despertada pelo estímulo, e então reagir, por sua vez, a essa resposta (MEAD, 1992, p. 171).

Mead afirma, como exposto na citação anterior, que a conexão entre sociedade e indivíduo se dá pela participação do ser humano nas atividades sociais, as quais implicam interação, comunicação simbólica e compartilhamento de experiências. A participação social e a adoção da atitude do outro são dois elementos centrais para a gênese do self, já que "o self pode existir somente para o indivíduo se ele assume os papéis sociais dos outros" (MEAD, 1981, p. 284).

A autoconsciência do "si mesmo" constitui-se numa construção intersubjetiva e simbólica, pois "um sujeito só pode adquirir uma consciência de si mesmo na medida em que ele aprende a perceber sua própria ação da perspectiva, simbolicamente representada, de uma segunda pessoa" (HONNETH, 2009, p. 131). Isto é, a autoconsciência é intersubjetiva porque a individuação se dá no recurso à socialização e, ao mesmo tempo, é simbólica porque implica configuração de sentidos e de significados por meio da prática linguística. Ressaltamos que essa construção não é isolada no tempo e no espaço. Ela emerge no quadro determinado das ações e das relações do indivíduo com os outros e com o meio no qual vive.

Mead entende que a consciência de "si mesmo" emerge da relação com os outros mediante a internalização dos papéis sociais e das expectativas generalizadas da comunidade à qual o sujeito pertence. Desse modo,

O self humano surge através da habilidade de adotar a atitude do grupo ao qual pertence - porque pode expressar-se a si mesmo em termos da comunidade à qual pertence e assumir as responsabilidades 
que pertencem à comunidade; porque pode reconhecer suas próprias obrigações como diferentes das de outros - isso é o que constitui o self como tal. [...] A estrutura da sociedade reside nesses hábitos sociais e nos convertemos em nós mesmos somente na medida em que podemos adotar esses hábitos sociais (MEAD, 1984, p. 33).

Percebemos, portanto, que é necessário que cada ser humano desenvolva o mecanismo de adotar a atitude do outro para que o self se desenvolva. Ou seja, ao adotar a atitude ou o papel dos outros membros do grupo social, o indivíduo passa a compartilhar integralmente das experiências desse grupo. Adotar a atitude do outro implica colocar-se na perspectiva do outro, colocar-se no lugar do outro. ${ }^{12}$

Para G. H. Mead, o caráter estruturante do self encontra-se no processo de comunicação simbólica mediante o qual um organismo reage ao gesto do outro, internalizando a atitude ou o papel social desse outro. Concomitante ao processo de comunicação, ele apresenta duas analogias ou etapas do processo de gênese do self: [i] o brincar (play) e o jogar (game). Tais atividades precedem a estruturação da noção de [ii] "outro generalizado", que consiste numa espécie de cenário organizado de convivência e numa forma de convenção universalizada da vontade coletiva da comunidade, a qual necessita ser internalizada por parte do indivíduo para que ele desenvolva um self. Além disso, [iii] Mead concebe o self enquanto uma estrutura dialética na qual o "eu" (I) reage ao "mim" (me), como veremos na sequência.

[i] O brincar (play) e o jogo organizado (game)

O brincar (play) constitui-se, para Mead (1992), numa ação fundamental da infância, que possibilita o surgimento de uma primeira percepção de si mesmo enquanto um eu, o desenvolvimento de comportamentos sociais, a inserção nas dinâmicas da vida em comunidade e a familiarização com as atividades básicas do grupo social ao qual pertence. É, por esses motivos, uma atividade central à estruturação da autoconsciência e

12 Para uma visão mais detalhada do processo de adoção da atitude do outro, sugerimos conferir o texto de Casagrande (2014, p. 65-69). 
da identidade pessoal que mantém sua influência por todo o transcorrer da vida (CASAGRANDE, 2014)..$^{13}$

Mead (1992) constatou que, por intermédio das brincadeiras, a criança adota vários papéis, um seguido de outro, de pessoas ou de animais presentes em sua vida quotidiana. Essa experiência possibilita-lhe ultrapassar a barreira do próprio corpo, mesmo que de modo rudimentar, em direção às atividades sociais. Ao participar da dinâmica da comunidade social, a partir das brincadeiras, a centralidade no próprio ego começa a ser rompida pela emergência de uma noção de um "outro" e de um "nós". Assim sendo, a fase do brincar, enquanto experiência do jogar com os papéis sociais disponíveis e conhecidos, representa a primeira experiência de saída de "si mesmo" e de apropriação de uma imagem de "outro" por parte da criança.

É importante perceber que o brincar, que antecede os jogos organizados, consiste, sempre, num brincar "algo", num brincar "alguma coisa".

A criança brinca de ser uma mãe, um professor, um policial; ou seja, como dizemos, adota diferentes papéis. [...] Por exemplo, brinca que está oferecendo algo e o compra; entrega-se uma carta e a recebe; dirige-se a si mesmo como um dos pais, como um professor; prendese como um policial. Tem uma série de estímulos que provocam nela os tipos de reações que provocam em outros. Toma esse grupo de reações e as organiza em um certo todo. Essa é a forma mais simples de ser outro para o próprio self(MEAD, 1992, p. 150-151).

Esse tipo de brincar livre, sem regras aparentes e por um período temporário, possibilita a organização de uma estrutura de conversação interior. Ao dizer algo, assumindo uma personagem, e ao responder em outra personagem, a criança desenvolve certa estrutura organizada de papéis sociais, condição fundamental para uma segunda fase de internalização do "outro", que se fundamenta em regras sociais e que possibilitará a estruturação da noção convencional de "outro generalizado".

A fase do jogo (game), por sua vez, refere-se às atividades com regras e com a participação de mais de um jogador. Podemos associar essa classe

13 Sobre o papel do brincar e do jogar, é possível encontrar extenso material na obra de Mead (2006; 1992, p. 144-163; 1981, p. 267-293). 
de atividade aos esportes coletivos organizados, nos quais uma equipe compete com outra equipe. Ao jogar, cada participante deve ser capaz de representar exitosamente um papel. O êxito ou a vitória de uma equipe sobre a outra dependem, simultaneamente, da capacidade de organização e de coordenação de seus membros, do atendimento às regras do jogo e da articulação dos papéis de cada um dos envolvidos.

A partir do jogo coletivo, a criança aprende a organizar o próprio comportamento, adequando-o ao dos outros jogadores, de modo que a atividade seja articulada e intencional. O jogador necessita adotar o papel que lhe é peculiar no jogo e, ao mesmo tempo, ser capaz de modificar ou trocar de papéis, no seu decorrer, para que seja capaz de antecipar os possíveis movimentos ou ações dos companheiros com fins de obter êxito ou, até mesmo, antecipar as jogadas e os papéis dos adversários, impedindo-os de vencer.

Mead apresenta uma partida de beisebol como exemplo de um game, comentando que nela cada jogador deve saber o que farão todos os demais jogadores, a fim de poder seguir seu próprio jogo. No beisebol, cada jogador precisa ser capaz de assumir seu papel em correlação com os demais e de acordo com regras já definidas. ${ }^{14}$

O jogo, em equipe e com regras estabelecidas, configura um avanço em relação ao brincar individual, pois amplia o horizonte da participação, da cooperação social e do descentramento de si mesmo por parte das crianças envolvidas. Para Mead (1992), o jogar representa uma situação arquetípica do desenvolvimento da consciência de si, porquanto articula a assunção de papéis sociais, a vivência das regras convencionais e a necessidade de um controle pessoal do comportamento com vistas à consecução de uma atividade que envolve cooperação, interação e metas comuns. Por isso,

No seu jogo, o jogador tem que ter uma organização desses papéis; do contrário, ele não pode jogar. $\mathrm{O}$ jogo representa uma passagem na vida da criança - da adoção dos papéis dos outros no jogo até a parte organizada - que é essencial para a consciência de si, na acepção completa do termo (MEAD, 1992, p. 152).

14 Para mais informações sobre o tema do "game", sugerimos conferir o texto de Mead (1992, p. 151-152). 
Por meio do jogo, organiza-se uma espécie de unidade de ação entre os participantes, a qual articula e controla as reações do indivíduo. Essa unidade de ação representa, para Mead (1992), o processo de introdução de um "outro" no processo, uma convenção da coletividade dos jogadores. Não se trata de um novo indivíduo, mas uma organização de atitudes e de ações supraindividuais, que envolvem todos os competidores no mesmo processo. Com a internalização da figura desse "outro" forma-se, mediante um processo de universalização, o que Mead (1992) denomina "o outro generalizado", como veremos na sequência.

\section{[ii] O "outro generalizado" (generalized other)}

O "outro generalizado" consiste numa representação simbólica da vontade coletiva organizada, que serve de orientação às atitudes dos distintos indivíduos implicados no processo social. Trata-se da dimensão normativa da comunidade social que se estrutura na forma de um horizonte de ação. Ou seja, "a atitude do outro generalizado é a atitude de toda a comunidade" (MEAD, 1992, p. 154) expressa em objetivos, valores, regras, costumes, sentidos e reações organizadas.

Mead (1992) entende que a adoção da perspectiva universalizada da comunidade, enquanto "outro generalizado", ocorre mediante um processo de internalização. A internalização constitui-se numa dinâmica formativa por intermédio da qual as instâncias controladoras do comportamento da sociedade migram do exterior para o interior do indivíduo. ${ }^{15}$ Ao internalizar a estrutura normativa do "outro generalizado", o ser humano está apto a desenvolver e progredir no pensamento abstrato e na configuração das estruturas do self.

Somente na medida em que ele [indivíduo] adotar as atitudes do grupo social organizado ao qual pertence, em direção à atividade social organizada e cooperativa, ou direcionada à série de atividades na qual

15 Entendemos que é fundamental distinguir dois conceitos que, no contexto da obra de G. H. Mead, são centrais: internalização e interiorização. Para tal, nos valemos de uma nota explicativa de Sass (2004, p. 260), nota número 27, que nos parece muito adequada: "Insistimos aqui que a diferença entre as noções de internalização - em que há um "sentido pessoal" na organização das estruturas externas - e de interiorização - que enfatiza a importação para o interior do sujeito das estruturas externas tal como se apresentam na experiência - ajuda-nos a compreender melhor o que está sendo posto em questão". 
esse grupo está ocupado, somente nessa medida ele desenvolverá um self pleno ou possuirá o tipo de self pleno que desenvolveu (MEAD, 1992, p. 155).

Percebemos no conceito de internalização do "outro generalizado" certa premência do processo socializatório em relação ao processo de individuação. A internalização da vontade coletiva generalizada consiste, também, no modo mediante o qual a sociedade exerce controle sobre seus membros. Destarte, não basta ao indivíduo estar num espaço geográfico definido, mas é necessário que viva como um membro de um grupo determinado, que se inculture, que corporifique em si os valores, as crenças, as regras e os objetivos próprios da comunidade à qual pertence.

[iii] A estrutura dialética do self: o "eu" $(I)$ e o "mim" $(m e)^{16}$

O desenvolvimento da consciência de "si mesmo" (self) pressupõe um processo de reflexibilidade do eu, o qual implica que o sujeito coloque a si mesmo enquanto objeto. Para detalhar esse processo, Mead postula uma bipartição do self, diferenciando o "eu" ( $I)$ do "me/mim" (me) e, ao mesmo tempo, explicitando a dinâmica dialética que se instala no interior da consciência do "si mesmo", na qual "o "eu" (I) reage ao self, que se originou por meio da adoção das atitudes dos outros" (MEAD, 1992, p. 174).

Na perspectiva apontada por Mead (1992), o que pode ser elevado à consciência é o "mim", aquela consciência de si que se originou da internalização das atitudes dos outros, especialmente da assunção da perspectiva generalizada do grupo social ou, em outros termos, do "outro generalizado". Logo, o "mim" consiste numa internalização social.

O "eu", enquanto dimensão pessoal que se contrapõe ao "mim", não é redutível à dimensão coletiva do "outro generalizado" que foi internalizada, tampouco é passível de captura pela consciência.

O "eu" é a reação do organismo às atitudes dos outros; o "mim" consiste na série organizada de atitudes dos outros que cada um assume.

16 Esse tópico específico foi também abordado por nós em outro texto (CASAGRANDE, 2014, p. 76-80), com algumas variações e nuances próprias. 
As atitudes dos outros constituem o "mim" organizado e, logo, um [indivíduo] reage frente a elas como um “eu” (MEAD, 1992, p. 175).

Mead (1992) entende que o "eu" $(I)$ constitui-se na dimensão não previsível do self, no elemento que nos identifica enquanto únicos e singulares que não é dado diretamente na experiência. Isto é, o "eu" $(I)$ não pode ser objeto da consciência. Ademais, o "eu" (I) emerge da ação criativa do indivíduo diante de uma situação social. Ele é uma reação que não pode ser prevista, tampouco antecipada, consistindo numa espécie de novidade do momento, do ineditismo da reação ao dado, sempre com uma orientação a um futuro indefinido.

O "eu", pois, nessa relação entre o "eu" e o "mim", é algo que, por assim dizer, responde a uma situação social que se encontra dentro da experiência do indivíduo. É a resposta que o indivíduo tem às atitudes que outros adotam em direção a ele, quando ele adota uma atitude em relação a eles. Assim sendo, as atitudes que ele adota em relação a eles estão presentes em sua própria experiência, porém sua resposta a elas conterá um elemento de novidade. $\mathrm{O}$ "eu" proporciona a sensação de liberdade, de iniciativa (MEAD, 1992, p. 177).

Além disso, Mead (1992) afirma que a ação ou a reação de alguém não podem ser previstas de antemão. Nessa perspectiva, a reação exata, a maneira específica como reagiremos diante de uma situação, somente pode ser evidenciada depois de sua consecução. Ou seja, a experiência do "eu" é completamente a posteriori, pois somente depois do ato concretizado e da sua consequente apreensão pela memória é que poderemos ter noção clara do realizado e, ao mesmo tempo, a consequência das ações e das reações do self.

No tocante ao "mim" (me), podemos afirmar que se trata do elemento consciente do self, visto sua existência imediata para o indivíduo na consciência. O "mim" permite a convivência social segundo os padrões estabelecidos, visto que contempla as convenções e as atitudes generalizadas dos outros. É a dimensão que mantém a estabilidade das ações e das reações do self, pois está pautado nas convenções da sociedade.

É interessante perceber que, na pessoa, o "eu" e o "mim" aparecem de formas distintas, mas mutuamente dependentes, tal qual parceiros de um diálogo. 
Não existiria um "eu", no sentido em que usamos esse termo, se não houvesse um "mim"; não haveria um "mim" sem uma reação na forma do "eu". Os dois, tal como aparecem em nossa experiência, constituem a personalidade. Somos indivíduos nascidos em certa nacionalidade, localizados em certo ponto geográfico, com tais relações familiares e tais relações políticas. Tudo isso representa certa situação que constitui o "mim"; porém, isso envolve, necessariamente, uma ação contínua do organismo em direção ao "mim" dentro do processo no qual reside (MEAD, 1992, p. 182).

A partir da separação do "eu" e do "mim", Mead (1992) procurou balancear a relevância das dimensões social e subjetiva no processo de estruturação da personalidade. Com isso, também resguardou a possibilidade da novidade, da criação e recriação de si e da comunidade e, ao mesmo tempo, excluiu qualquer tendência ao determinismo social, visto que o "eu" (I) mantém-se enquanto uma dimensão não redutível ao "mim" (me) convencional. Ficou protegida a responsabilidade de cada ser humano em relação aos seus próprios atos, pois somente pode ser imputável o sujeito que tem liberdade de escolha numa situação dada.

\section{A educação e os processos de formação em G. H. Mead}

Mead (1992) possui uma interessante história relacionada ao campo educacional. Em 1894, mudou-se para Chicago e passou a ocupar a função de professor no Departamento de Filosofia e de Psicologia na Universidade de Chicago. Nessa universidade, construiu uma respeitada carreira de docente e pesquisador, compartilhando as perspectivas teóricas do pragmatismo com outros destacados pensadores, como William James, Charles S. Pierce e John Dewey. ${ }^{17}$ Nesse período, teve envolvimento concreto com o mundo da educação, ${ }^{18}$ aliando teoria e prática, especialmente com a intenção

17 Sobre esse assunto, sugerimos consultar Pragmatism and Educational Research (BIESTA; BURBULES, 2003).

18 Biesta e Tröller (2008, p. 2) destacam o envolvimento prático de Mead com "a Escola Laboratório de Dewey", bem como sua atuação como "presidente da Associação de Pais da Escola", durante vários anos. Silva (2010, p. 185) aponta, entre as atividades ligadas ao mundo da educação concretizadas por Mead, seu envolvimento com a "Escola 
de resolver os problemas concretos que se apresentavam na sua tarefa de professor e pesquisador.

Os escritos de Mead destacam a dimensão social como uma característica fundamental à estruturação da personalidade. Quando Mead refere-se à educação, isso também ocorre. Ele expõe essa compreensão ao afirmar que "a situação implicada na instrução, e na psicologia dessa instrução, é uma situação social" (MEAD, 1981, p. 116). Ou seja, a educação possui caráter social, consistindo num processo interativo e simbólico, por meio do qual os educandos respondem a uma situação organizada de aprendizagem. O princípio fundamental da educação também respeita a concepção teórica de que a intersubjetividade precede e constitui a subjetividade, ou, nas palavras de Mead (1981, p. 122), "[...] a criança não se torna social pela aprendizagem; ela deve ser social para aprender". ${ }^{19}$ Entendemos que essa percepção de Mead quanto aos processos formativos continua fecunda para analisarmos o papel da educação em nossos dias. ${ }^{20}$

Além disso, de acordo com Mead, das interações sociais origina-se o material para a formação criativa de conceitos e significados, uma tarefa fundamental da educação. Nessa perspectiva, a educação também consiste num processo de criação e de transformação de significados mediante a interação comunicativa de seus membros. No rol dos significados necessários a serem desenvolvidos, inclui-se a aprendizagem de um método de pensar, a emergência da consciência reflexiva e a internalização das atitudes e dos papéis sociais que facultam ao indivíduo a formação de uma identidade de si mesmo. No que tange à instituição escolar, Mead (1992) atribui-lhe um papel privilegiado enquanto espaço e tempo de socialização, de interação e de formação das estruturas do eu.

Hospital, que estava sob a supervisão do Departamento de Neurologia e Filosofia da Universidade de Chicago, desde a sua criação em 1890 [...] para prover um adequado treinamento aos alunos com dificuldades de aprendizagem".

19 Nesse texto, Mead (1981, p. 122) afirma: "So far as education is concerned, the child does not become social by learning. He must be social in order to learn". Omitimos, em nossa tradução, a parte inicial da primeira oração por considerá-la desnecessária ao entendimento do texto.

20 A relação entre educação e psicologia social na obra de G. H. Mead foi analisada por Odair Sass (2001, p. 133 - 138). Além disso, essa relação foi também abordada em Casagrande (2014, p. 81-119), embora com aspectos distintos daqueles aqui apresentados. 
Embora Mead (1992) não tenha escrito um tratado sistemático sobre teoria educacional, seus artigos e a transcrição de suas aulas de Filosofia da Educação, na Universidade de Chicago, conformam um corpo teórico que contém vários insights originais. ${ }^{21}$ Nessas aulas, Mead (1992) dá destaque especial a três elementos que, sincronizados e conjuntamente, conformam um olhar diferenciado acerca da educação: a importância da dimensão social e da organização da vida da comunidade nos processos formativos, com seus valores, ritos de iniciação e de transmissão dos conteúdos culturais, a linguagem enquanto interação social e campo de produção e de reprodução de significados, de sentidos e de conceitos, o processo de formação dos significados e, correlativamente, da consciência de si mesmo.

Essas primeiras ideias relativas à educação sinalizam o modo distinto a partir do qual Mead (1992) concebeu o processo formativo do ser humano, considerando o destaque atribuído à interação, à construção coletiva de significados e à mediação simbólica. Tendo presentes esses primeiros elementos, apresentaremos a seguir [i] o que Mead compreende por educação e a relação da educação com a formação de significados. Na sequência, [ii] comentaremos a importância atribuída por Mead ao brincar e ao jogar como instâncias formativas.

[i] Educação, interação e o processo de formação de significados

Mead (1992) compreende a educação escolar enquanto uma ação sistemática, intencional simbólica e interativa. Ela constitui-se numa resposta organizada da comunidade humana com vistas à sua manutenção e ao seu processo evolutivo. Por meio da educação, uma sociedade pode ensinar aos seus novos membros maneiras de resolver problemas concretos que thes advém, tanto na esfera da cultura e da ciência, quanto da moralidade e da política. Isto é, a instituição educacional é o instrumento privilegiado que o grupo humano lança mão para auxiliar no processo formativo das novas

21 Referimo-nos, neste momento, à obra The Philosophy of Education (MEAD, 2008), organizada e introduzida por Gert Biesta e Daniel Tröhler. Trata-se de uma coletânea de 38 aulas do curso de Filosofia da Educação proferidas por G. H. Mead, na Universidade de Chicago, nos anos de 1910 e 1911, que foram transcritas por uma da aluna que assistiu ao curso (BIESTA; TRÖHLER, 2008, p. 3-4). 
gerações, especialmente no que tange à aprendizagem de significados, à socialização e à estabilização de identidades pessoais.

$\mathrm{Na}$ Universidade de Chicago, Mead (1992) foi professor do curso de Filosofia da Educação. Na ementa desse curso, afirmou que sua intenção era tratar do problema da socialização gradual da criança e das implicações que a educação tinha nesse processo. Para tanto, uma das primeiras tarefas era recolocar uma concepção social de educação que reconhecesse a criança e a sociedade, ao mesmo tempo, sob o prisma da comunicação e da construção social de significados. ${ }^{22}$

Para Mead, na educação, a criação de significados é possível por intermédio da interação e da resposta do educando a uma atitude, uma ação ou um papel do outro, pois "a consciência de significados surge somente na interação com os outros" (MEAD, 2008, p. 152). É importante destacar que não se trata da ação de "descobrir" ou de "passar" um significado de um sujeito para o outro, do educador ao educando, mas de um processo criativo, de construção comunicativa de conceitos comuns. É o educando que cria significados a partir da interação que se estabelece no espaço e no tempo escolar, porquanto "a educação é intercâmbio de ideias, é conversação, ambas pertencentes ao universo do discurso" (MEAD, 1981, p. 118). Assim, podemos dizer que o educando cria significados mediante suas reações e respostas às situações de aprendizagem com as quais é confrontado e pelas quais é desafiado ou instigado por meio da ação mediadora do educador.

Como temos visto, o processo de formação dos significados é social e depende de situações interativas entre os sujeitos da educação. Nesse sentido, a organização das situações e dos espaços de experiência e de aprendizagem, na escola, torna-se fundamental. Por conseguinte, a escola necessita prover currículos e metodologias que privilegiem a criação de significados por meio da interação, da mediação pedagógica e das experiências significativas. Além disso, é necessário atenção ao papel desempenhado pelo educador que, entre outros aspectos, inclui a função de mediar e desafiar os educandos para que reflitam e respondam aos estímulos de modo cada vez mais qualificado, tornando possível a emergência de novos conceitos ou de uma consciência de significados diferenciada.

22 Conforme extrato do Registro Anual da Universidade de Chicago, para os anos de 19051906, presente em Biesta e Tröhler (2008, p. 4-5). 
Nos escritos de Mead (1992) é possível encontrar uma distinção entre o que denomina "velha educação" e "educação atual". ${ }^{23}$ Para Mead (1992), a "velha educação" negligencia a participação criativa da criança no processo de aprendizagem, pois privilegia a disciplina e a associação de ideias abstratas e descontextualizadas em detrimento do contato direto da criança com objetos, experiências e vivências pedagógicas. Por outro lado, a "educação atual" necessária é aquela que possibilita experiências concretas, visto que é por meio do contato direto com os objetos e com o mundo que os processos de reflexão e de abstração originam-se. A percepção de Mead acerca dos processos educacionais leva Biesta e Tröhler (2008, p. 8) a esta afirmação:

Nós podemos ver em tudo isso uma teoria da educação na qual a criança não é, simplesmente, o lado receptor do processo. A educação não consiste em transferência de significados do professor ao estudante, dos pais às crianças, da geração atual às próximas gerações. A educação é um processo de comunicação no qual as crianças são muito mais criadoras de significados do que o são os adultos. Para Mead, as crianças não são um recipiente vazio que deve ser preenchido. As crianças são, em última instância, a fonte de renovação e de novos significados.

Mead (1992) concebe a escola como uma instituição social. ${ }^{24}$ As instituições sociais cumprem importante papel social à medida que representam uma forma de organização de atitudes e atividades sociais, garantindo a experiência de uma comunidade, com valores, regras e momentos de interação. Essas instituições, entre as quais está a escola, constituem parte vital na evolução do indivíduo e da sociedade, pois se referem às manifestações formais do processo evolutivo, que garantem os processos de socialização e de individuação. Desse modo, a escola compartilha, igualmente, a função de garantir a integração social, a formação para a cidadania e para a participação democrática.

23 O termo empregado por Mead é "Old education" em oposição a "Our education" (MEAD, 2008, p. 92). A crítica se dirige especialmente aos seguidores da pedagogia de Herbart, "os quais possuem uma percepção apenas da dimensão intelectual do ensino, sem perceber a natureza e a base social do mesmo" (MEAD, 2008, p. 174).

24 Para Mead, uma instituição social "representa uma resposta comum por parte de todos os membros de uma comunidade a uma situação particular” (MEAD, 1992, p. 261). 
A escola é o mais importante instrumento de que dispõe uma comunidade se ela realmente quiser dotar seus jovens das aptidões cognitivas e morais necessárias para o exercício esclarecido da cidadania. Um cidadão atuante é um indivíduo capaz de enfrentar com racionalidade os problemas sociais, de levar em consideração todos os valores em jogo e de ser capaz de reconstruir essa situação problemática transcendendo a ordem específica da sociedade em que vive (SILVA, 2009, p. 197).

O ser humano, diferente de outras classes de animais, necessita que a sociedade, a partir de suas instituições, organize processos específicos que objetivem o cuidado, a proteção e o ensino aos novos membros do grupo social, especialmente no longo período de infância. A educação, nesse sentido, emerge como elemento essencial da organização e da manutenção da vida dos indivíduos e dos distintos grupos sociais. Ao nascer, a criança não possui os instintos de sobrevivência já presentes em outras espécies, o que denota a necessidade de que a gerações adultas organizem processos de ensino e de aprendizagem que capacitem os novos indivíduos a sobreviverem, reagirem e adaptarem-se ao mundo em que estão adentrando.

É necessário destacar, novamente, a centralidade do papel da intersubjetividade e da interação como instâncias formativas nos textos de Mead. Nesse sentido, Biesta (1998, p. 93) entende que "a principal conclusão pedagógica a ser extraída dos escritos de Mead é o argumento de que educação é interação social". Ou seja, é no convívio social que a identidade do "eu" pode ser moldada, visto que a situação social é condição para a emergência da consciência, da racionalidade e do self. Assim, o espaço-tempo escolar tem importância fundamental ao possibilitar às crianças experiências de interação, convivência e socialização.

[ii] A dimensão lúdica do processo formativo

As atividades lúdicas, como o brincar livre (play) e o jogar de forma organizada (game), configuram-se em situações arquetípicas da formação e do desenvolvimento do self. A importância conferida à ludicidade decorre da centralidade atribuída por Mead (2006) aos gestos e às situações interativas 
espontâneas, características da fase infantil da criança e presentes, sobremaneira, nas atividades lúdicas. Isto é, o brincar e o jogar são considerados por Mead desde a perspectiva de seus efeitos socializadores e formativos.

Segundo Mead, "o brincar consiste na essência do ato da criança" (MEAD, 2006, p. 24). Ele percebe que no agir infantil, diferente do agir adulto, preponderam as dimensões afetivas e estéticas do ato, em detrimento da dimensão intelectual. Essa percepção, longe significar uma desvalorização da ação infantil, salienta que a realidade é aprendida, elaborada e vivida desde uma perspectiva diferenciada por parte da criança, que pode ser mais bem compreendida se associada às situações lúdicas.

O brincar tem um papel decisivo no comportamento da criança, sendo mais do que um estágio no desenvolvimento do self. O brincar é uma organizada e identificável atividade humana que começa na infância, sendo necessária no transcorrer de toda a vida. Tem um papel fundamental na infância, na conexão entre as emoções, o estético e as atitudes, em direção à sociedade. Ele permite que os símbolos se transformem em significado e comportamento (DEEGAN, 2006, p. LVI).

Para Mead, a dimensão lúdica representa um princípio-chave que necessita ser incorporado à vida escolar, pois mediante essa classe de atividades, como as brincadeiras e os jogos, é possível a internalização dos diversos papéis sociais disponíveis. O brincar e o jogar são instâncias fundamentais ao processo de socialização, consistindo nos princípios pedagógicos a partir do quais a educação deve ser conduzida. Nesse sentido, afirma Mead (2006, p. 42):

Com referência ao brincar, enquanto princípio a partir do qual a educação deveria ser conduzida, nós não entendemos que a criança deveria ser abandonada à própria influência em relação a si mesma, mas que nós deveríamos organizar esses estímulos para que eles respondam ao crescimento natural do organismo da criança, tanto com relação aos objetos pelos quais se interessa, quanto nas relações que ela possui com os outros no processo de vida que ela tem de pôr em prática.

Ao reafirmar a importância do brincar e do jogar na infância, Mead (2006) realiza uma crítica contundente ao modelo escolar da sua época, um 
modelo tecnificado e por demais hermético, que não explorava adequadamente as dimensões lúdica e estética enquanto momentos formativos. A concepção educacional vigente estava mais alinhada ao modelo do mundo do trabalho que a uma compreensão que abarcasse integralmente a vida da criança, com a devida atenção ao brincar. Mead (2006), por sua vez, defendia um método educativo de estimulação natural, no qual os interesses estariam direcionados aos objetos em si mesmos e não aos fins, como no caso do trabalho e da técnica.

Devemos salientar que, para Mead (2006), o brincar, junto com o trabalho e a arte, enquadra-se no rol das atividades significativas da vida humana. $\mathrm{O}$ brincar distingue-se de ambos pela absoluta espontaneidade e fascinação no imaginário da criança, não necessitando ser elevado à consciência para ter valor em si, pois "a completa espontaneidade, a fascinação e o valor do brincar estariam perdidos se cada elemento fosse levado à consciência da criança" (MEAD, 2006, p. 34). Por isso, o princípio do trabalho não pode ser aplicado como um modelo nos primeiros anos da infância, sob pena de sabotarmos a criatividade e a espontaneidade das crianças. Essa concepção leva Silva (2009) a apontar a noção do brincar como um princípio-chave na educação, nos seguintes termos:

Na opinião dele [Mead], a escola devia adotar a noção do brincar como princípio-chave, no sentido de que os estímulos provocados pelos objetos do ambiente devem ser dispostos de maneira a responderem ao desenvolvimento natural do organismo das crianças, tanto com respeito aos objetos pelos quais elas sucessivamente vão adquirindo interesse, quanto com as relações recíprocas que cada uma terá de levar adiante no processo de viver (SILVA, 2009, p. 189).

Sendo o brincar um princípio natural do desenvolvimento dos indivíduos, é fundamental que a escola proponha um método de estimulação natural da criança, no qual os interesses estejam direcionados aos objetos em si mesmos e não nos fins que representam. Desde a perspectiva apontada por Mead, o brincar justifica-se, na educação inicial, por si mesmo, já que muito além da perspectiva do trabalho, da organização e da disciplina, o brincar possibilita a interação, a internalização de atitudes e papéis sociais, o desenvolvimento da criatividade e do espírito de cooperação no grupo, favorecendo a emergência da consciência de "si mesmo" e da identidade pessoal. 


\section{Considerações finais}

Em consonância com o que argumentamos no decorrer deste artigo, foi possível perceber que a noção de "interacionismo simbólico", nos escritos de Mead (2006), pressupõe o reconhecimento categórico do caráter social da vida humana e da anterioridade da sociedade em relação ao indivíduo. Ademais, a comunicação, a linguagem e a intersubjetividade possuem papel central na formação do ser humano e da sociedade, visto que a estruturação dos significados, da inteligência, da racionalidade e do self se dão sob o fundamento da interação simbólica.

Mead (2006), embora não tenha criado o termo "interacionismo simbólico", apresentou uma compreensão original da estruturação da identidade pessoal. Concebeu a formação do self mediante a inserção dos indivíduos em processos de socialização, por intermédio da interação, da cooperação e da comunicação. Desse modo, somente num contexto interativo o sujeito pode converter-se em self, em sujeito com consciência de "si mesmo", pois o acesso ao "eu" é sempre mediado por um "mim", uma consciência de "si mesmo" que advém da introjeção das demandas, dos papéis e das perspectivas generalizadas da comunidade. Nesse processo, o brincar e o jogar são analogias do modo mediante o qual o self se forma e desenvolve suas estruturas internas.

Sob a perspectiva da educação, entendemos que os pressupostos teóricos apontados nos escritos de Mead (2006) possuem fecundidade para embasar uma leitura diferenciada dos processos, das práticas e das intencionalidades que permeiam o campo educacional de nosso tempo. Chamamos a atenção especialmente ao valor fundamental da interação, da convivência social e dos processos de socialização que podem ser desenvolvidos no ambiente escolar. Além disso, cabe destacar o valor da dimensão lúdica no processo escolar, visto que, em atividades como o brincar e o jogar, é facultado à criança experimentar livremente a espontaneidade, a imaginação e a criatividade, além de fazer a experiência do intercâmbio de papéis sociais, fundamental para a internalização das estruturas sociais do self. 


\section{Referências}

BIESTA, G. J. J. Mead, intersubjectivity, and education: the early writings. Studies in Philosophy and Education. Springer Netherlands, v. 17, n. 2-3, p. 73-99, Jun. 1998. Disponível em: <http://www.metapress.com/content/ p2437140t885hh20/fulltext.pdf>. Acesso em: 08 maio 2010.

. Radical Intersubjectivity: reflections on the "different" foundation of education. Studies in philosophy and education. Dordrecht, v. 18, n. 4, p. 203-220, Jul. 1999. Disponível em: <http://www.metapress.com/content $/ 2 \mathrm{rwhm} 9 \mathrm{~g} 9 \mathrm{nqgy} / \mathrm{p}=7 \mathrm{ff1} 928 \quad 4626049 \mathrm{~d} 28 \mathrm{e} 23 \mathrm{~b} 7 \mathrm{c} 35523 \mathrm{afea} \& \mathrm{pi}=0>$. Acesso em: 08 de maio 2010.

BIESTA, G. J. J.; BURBULES, n. C. Pragmatism and educational research. Lanham: Rowman \& Littlefield, 2003, 128p.

BIESTA, G. J. J.; TRÖHLER, D. George Herbert Mead and the development of a social conception of education. In: MEAD, G. H. The philosophy of education. Boulder: Paradigm Publishers, 2008, p. 1-16.

BLUMER, H. Symbolic interactionism: perspective and method. Berkeley: University of California Press, 1969, 208p.

. George Herbert Mead and human conduct. Walnut Creek: Altamira Press, 2003, 197p.

CASAGRANDE, C. A. G. H. Mead \& a educação. Belo Horizonte: Autêntica Editora, 2014, 127p.

CASAGRANDE, C. A.. A formação do eu em Mead e em Habermas: desafios e implicações à educação. 2012, 197f. Tese (Doutorado em Educação) - Pontifícia Universidade Católica do Rio Grande do Sul, Programa de Pós-Graduação em Educação, Porto Alegre, 2012.

COOK, G. A. George Herbert Mead: The making of a social pragmatist. Urbana: University of Illinois Press, 1993, 231p.

DEEGAN, M. Jo. Play from the perspective of George Herbert Mead. In: MEAD, G. H. Play, school, and society. New York: Peter Lang Publishing, 2006, p. XIX-CXII. 
HABERMAS, J. Teoria do agir comunicativo: racionalidade da ação e racionalização social. São Paulo: WMF Martins Fontes, 2012, v. 1. 704p.

. Pensamento pós-metafísico: estudos filosóficos. 2. ed. Rio de Janeiro: Tempo Brasileiro, 2002, 271p.

HONNETH, A. Crítica del agravio moral: patologías de la sociedad contemporánea. Buenos Aires: Fondo de Cultura Económica, 2009, 464p.

JOAS, H. G. H. Mead: a contemporary re-examination of his thought. Massachusetts: The MIT Pres Cambridge, 1997, 268p.

. Interacionismo simbólico. In: GIDDENS, A.; TURNER, J. Teoria social hoje. São Paulo: UNESP, 1999, p. 127-174.

MEAD, G. H. Mind, self, and society: from the standpoint of a social behaviorist. Chicago: The University of Chicago Press, 1992, 401p.

. Espíritu, persona y sociedad: desde el punto de vista del conductismo social. Barcelona: Paidós, 1973, 403p.

. Selected writings. Chicago: The University of Chicago Press, 1981, 416p.

. On social psychology. Chicago: The University of Chicago Press, 1984, 358p.

. Play, school, and society. New York: Peter Lang Publishing, 2006, $157 \mathrm{p}$.

. The philosophy of education. Boulder, CO: Paradigm Publishers, 2008, 196p.

MILLER, D. L. George Herbert Mead: self, language and the world. Austin: University Of Texas Press, 1973, 280p.

MORRIS, C. George H. Mead as social psychologist and social philosopher. In: MEAD, G. H. Mind, self, and society: from the standpoint of a social behaviorist. Chicago: The University of Chicago Press, 1992, p. IX-XXXV. 
NUNNER-WINKLER, G. Formação da identidade em tempos de mudanças velozes e multiplicidade normativa. Educação, Porto Alegre, v. 34, n. 1, p. 56-64, jan./abr. 2011.

SASS, O. Crítica da razão solitária: a psicologia social segundo George Herbert Mead. Bragança Paulista: Universitária São Francisco, 2004, $304 p$.

. Psicología social y educación: la perspectiva pragmática de George Herbert Mead. Revista educación y pedagogía, Medellín, n. 26/27, p. 123-140, 2001. Disponível em: $<\mathrm{http}: / /$ aprendeenlinea.udea.edu.co/revistas/index.php/revistaeyp/article/view/11197/10264>. Acesso em: 23 nov. 2015.

SILVA, F. C. da. Em diálogo com os tempos modernos: o pensamento político e social de G. H. Mead. Rio de Janeiro: Tempo Brasileiro, 2009, 304p. . School and democracy: a reassessment of G. H. Meads educational ideas. Etica \& Politica/Ethics \& Politics. Edizioni Universitá di Trieste, XII, p. 181-194, 2010. Disponível em: <http://www.openstarts.units.it/ dspace/bitstream/10077/4690/1/CarreiraDaSilva_E\%26P_XII_2010_1. pdf $>$. Acesso em: 27 fev. 2012.

Data de registro: 08/02/2014

Data de aceite: 17/11/2014 